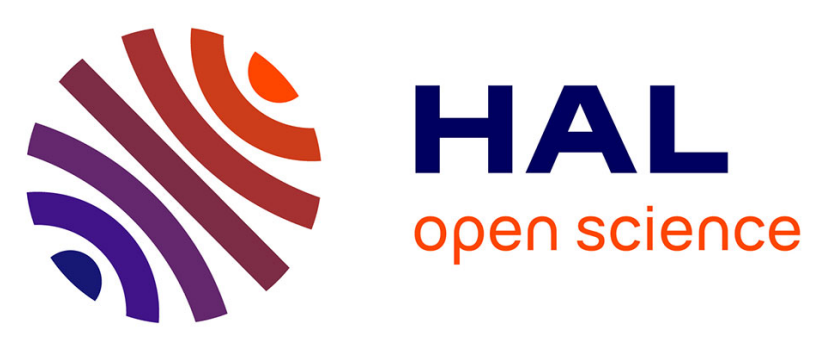

\title{
Special Issue on Language Production and bilingualism. In memoriam of Albert Costa. Kristof Strijkers, Arturo Hernandez, Albert Costa
}

\section{To cite this version:}

Kristof Strijkers, Arturo Hernandez, Albert Costa. Special Issue on Language Production and bilingualism. In memoriam of Albert Costa.. Journal of Neurolinguistics, 2021, 58, pp.100966. 10.1016/j.jneuroling.2020.100966 . hal-03084927

\section{HAL Id: hal-03084927 https://hal.science/hal-03084927}

Submitted on 23 Dec 2020

HAL is a multi-disciplinary open access archive for the deposit and dissemination of scientific research documents, whether they are published or not. The documents may come from teaching and research institutions in France or abroad, or from public or private research centers.
L'archive ouverte pluridisciplinaire HAL, est destinée au dépôt et à la diffusion de documents scientifiques de niveau recherche, publiés ou non, émanant des établissements d'enseignement et de recherche français ou étrangers, des laboratoires publics ou privés. 
Special Issue on Language Production and Bilingualism. In memoriam of Albert Costa.

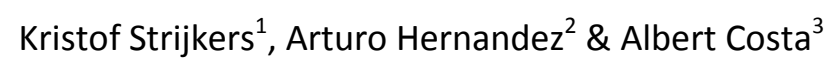

${ }^{1}$ Aix-Marseille University \& Centre National de la Recherche, Laboratoire Parole et Langage (LPL), Aix-en-Provence, France.

$$
{ }^{2} \text { University of Houston, Houston, TX, USA. }
$$

${ }^{3}$ Center for Brain and Cognition, Pompeu Fabra University, ICREA, Barcelona, Spain.

*Corresponding Author:

Dr. Kristof Strijkers

Aix-Marseille University \& CNRS

Laboratoire Parole et Langage (LPL - UMR 7309)

5 Avenue Pasteur

13100 Aix-en-Provence 
France

Email : kristof.strijkers@gmail.com

[Kristof]: 'It's early December 2018. I just had a Skype-meeting with my former mentor and friend, Albert Costa, where we finalised our list of potential contributors for a new Special Issue on Language Production we were planning for the Journal of Neurolinguistics. The goal of this Special Issue, following up on the success of a Special Issue we edited together 7 years before (Strijkers \& Costa, 2011), was to address the latest advances in the cognitive neuroscience of language production, with a special focus on how neuroscientific methods contributed to our understanding of the cognitive mechanisms underpinning the production of language. A week later Albert was no more...

This was both devastating and surrealistic. I literally just talked to the guy, hearing for the $100^{\text {th }}$ time how Lionel Messi's FC Barcelona was the best the football team in history. I threw the plans and outline for our special issue in the trash can. I wasn't up for that anymore... However, after the first shock of Albert's unexpected death had passed, and thanks to the support of editor-in-chief Ping Li and the editor-in-chief who replaced Ping at the Journal of Neurolinguistics in 2019, Arturo Hernandez (and who kindly enough proposed to help me out editing the special issue), I decided it was necessary to continue with this Special Issue.'

[Arturo]:'There is an inextricable tie that binds the three of us together. I had been nominated for the Editor position at JNL but had learned that Albert had been appointed. It seemed appropriate to me that Albert be the new Editor-In-Chief given the experience he had as Associate Editor. Then one day I received notice that Albert could no longer serve as Editor with a request about the possibility that I take over the position in a few weeks. Albert and I had sat at the same table a few months earlier at a symposium on the Bilingual Brain to discuss our work and the two books we had written with the same title. His was in Spanish and mine in English. Sometime later I received a call about 
my "new" book, The Bilingual Brain, that was sent out for a review. A journalist wanted to know more about it. I told him I had an old book from 2013. Then it dawned on me that Albert's book had a translation entitled The Bilingual Brain. It reminded me that Albert's shoes were difficult to fill and that in some way I was carrying the torch and continuing to move the field ahead in his stead. I was always impressed with his clarity of thought and the way in which he so forcefully and elegantly made his points. This special issue is a result of all the hard work that Kristof and him started. I was just hanging out at the corner minding my own business when the two of them drove up and encouraged me to hop on in.'

We could hear Albert growl: "Cabrones! Finish the job!". So we did, but rather than just be a Special Issue about the cognitive neuroscience of language production, we wanted it to be a testimony in his honour and additionally invited long-time collaborators and friends of Albert to contribute the issue; the Special Issue on language production and bilingualism in memoriam of Albert Costa was conceived, and more than 18 months later we are glad that we have 'finished the job'.

The result is a collection of 10 articles, both experimental and reviews, addressing the current stateof-the-art in the cognitive neuroscience of language production and bilingualism, with a special focus on topics related to Albert's work. In the first article, Nozari and Pinet (2020) give an extensive overview of the behavioural and neurophysiological data related to the co-activation of lexical representations in speech production. The authors point out three problematic assumptions linked to the interpretation of these data, namely (1) a linear framework to interpret co-activation, (2) the reliance on competitive selection, and (3) the circularity between tasks upon which model assumptions are based and tasks to test those model assumptions. The authors propose that a fruitful way forward is to dissociate mandatory processes (e.g., spreading activation) from optional ones (e.g., lexical competition) and apply this idea to the study of spreading activation, speech monitoring and language control. In the second article of this Special Issue, continuing with the 
topics of the neurobiology of word production and semantic interference, Ries and colleagues (2020) analyse intracranial electrocorticography data of 5 patients performing the blocked cyclic naming task with a graph signalling approach. Employing this novel approach the authors observed that picture naming (in general) resulted in robust left fronto-temporal connectivity, but the semantic interference effect resulted in highly variable connection weights and region pairs across individuals. The authors conclude that fronto-temporal connectivity plays a functional role during lexical access in speech production, and specific intra-frontal connectivity seems particularly relevant to explain lexical retrieval difficulty. Still within the realm of the spatiotemporal dynamics of word production, in the third article of this series, Piai et al. (2020) investigated the oscillatory dynamics underpinning picture naming in constraining sentential contexts and found that naming latencies were faster in constraining (compared to neutral) contexts. Importantly, when exploring the oscillatory dynamics of this constrained picture naming, the authors observed a decrease in alphabeta power for constrained picture naming when just before an unrelated auditory distractor was presented, but this effect was delayed when the auditory distractor was semantically related. The authors conclude that alpha-beta power decreases in (constrained) word production reflect lexicosemantic retrieval operations. In the fourth on the cognitive neuroscience of language production, Hitomi and colleagues (2020) explored the usefulness of functional near-infrared spectroscopy (fNIRS) to study the neural underpinnings of word production. In a first experiment they investigated the classical picture-word interference (PWI) paradigm and found semantic interference effects in typical language production regions such as the inferior frontal cortex (IFG), mid temporal gyrus (MTG) and the precentral cortex. In a second experiment they sought to consolidate these findings running the same experiment but including $L 2$ naming. While the semantic interference effects in IFG and precentral gyrus overall replicated, in the second experiment no semantic interference effect in the MTG was observed. Based on these patterns of results, the authors discuss the usefulness as well as methodological concerns for using fNIRS in language production research. Finally, forming the bridge between the articles on language production and the subsequent ones on 
bilingualism, in the fifth article, David Kemmerer (2019) explores three different types of crosslinguistic semantic diversity and its implications for the neurobiology of language production. The cross-linguistic nature of (1) semantic field partitions, (2) semantic conflation cases, and (3) grammatically obligatory semantic categories are explored in order to gain insights how messages are tuned to the target language and its consequences for neurolinguistic research on speech production.

Turning to the topic of bilingualism, in a perspectives article, Zeng et al. (2020) propose that the bilingual lexicon is not only integrated at the levels of words, but also at the multiword phrase level. The authors review evidence about multiword phrase representations across languages and based on the parallels with single word representations propose an integrated lexicon in bilinguals. Next, two accounts are offered which could explain the data of multiword phrase utterances between L1 and L2, namely an online activation model and a learning-based model, and proposals are provided how to differentiate and empirically test these two models. In the seventh article of this Special Issue, Ahn and colleagues (2020) treat a classical topic in the bilingual literature and to which Albert Costa had dedicated much of his career: bilingual language control. While traditionally a much investigated topic within modality (especially language production), Ahn et al. (2020) approach the issue across the modalities and ask the question how much of the bilingual language control mechanisms are shared between production and comprehension. Comparing eye-movement and intrusion errors for language switch costs in a silent sentence reading task and reading aloud task, respectively, the authors observed that those bilinguals making more intrusion errors during production, did not display different eye-movement patterns for switch trials in the silent reading task. Based on this pattern, they conclude that language control relies on modality-specific mechanisms in the bilinguals' brain. Still on the topic of bilingual language control, in the eight article, Chen and colleagues (2020) investigated individual differences on the neurobiology of language control in speech production. In a fMRI experiment, speakers engaged in a bilingual picture 
naming task, subsequently underwent 8 days of training on language switching, and afterwards performed the same bilingual picture naming task with $\mathrm{fMRI}$ to investigate the neural learning effect of language switching training. The authors found that language switching training enhanced the neural correlates of reactive control mechanism. Also the neural correlates of proactive control were enhanced, but this effect was restricted to those bilinguals with lower proficiency. This study hereby highlights neural plasticity in language control and how this neural plasticity is affected by L2 proficiency in bilingual language production. In the ninth article of the Special Issue, another important topic of Albert's research is addressed, namely the bilingual naming advantage (i.e., monolinguals naming pictures faster than bilinguals). Baus and collaborators (2020a) compared the electrophysiological correlates of the word frequency effect in monolinguals, L1 bilinguals and L2 bilinguals. They observed an earlier ERP onset of the word frequency for the monolingual group compared to the bilingual participants, but no differences between the bilinguals naming in their L1 and L2. In addition, when contrasting error-trials versus correct trials at response onset, only the monolingual speakers displayed a frontal error-related negativity. Taken together, the data suggest that the bilingual naming disadvantage originates at the lexical level, which is delayed in bilingual compared to monolingual speakers, and that a difference in the efficiency of speech monitoring between bilinguals and monolinguals could be involved in the slower naming latencies for the former compared to the latter group. Finally, to conclude the Special Issue, a review article by Zhang et al. (2020) explores the relationship between bilingualism and aging. The authors discuss a range of studies that envisaged the impact of being a bilingual on age-related cognitive and neural decline, with a special focus on which factors may explain inconsistencies across the literature of the neurocognitive benefits of bilinguals on aging. The authors conclude that individual differences in language proficiency, in particular the factors frequency of language use and frequency of language switching, can explain the diverging results concerning the role of bilingualism as cognitive and neural reserve. 
To conclude this Special Issue, an unique outro is included where many of Albert's former students bring in remembrance with short paragraphs the influence Albert had on their careers and person

(Baus et al., 2020b). Overall, we hope this Special Issue will offer interesting insights regarding the cognitive neuroscience of language production and bilingualism and succeeds in inflicting novel questions and research; but above all, we hope this Special Issue serves as a documented testimony of the influential and special researcher Albert Costa was in these domains of investigation, and that we left behind a piece of science in his memory of which he could have been proud. You will be missed.

\section{Acknowledgements}

Kristof Strijkers was supported by two research grants of the 'Agence National de la Recherche ' (ANR): ANR-16-CE28-0007-01 and ANR-18-FRAL-0013-01.

\section{References}

Ahn, D., Abbott, M. J., Rayner, K., Ferreira, V. S., \& Gollan, T. H. (2020). Minimal overlap in language control across production and comprehension: Evidence from read-aloud versus eye-tracking tasks. Journal of Neurolinguistics, 54, 100885.

Baus, C., Calabria, M., Duñabeitia, J., Hernandez, M., Ivanova, I., Mahon, B.,... \& Strijkers, K. (2020). Memories: Albert Costa's legacy. Journal of Neurolinguistics.

Baus, C., Santesteban, M., Runnqvist, E., Strijkers, K., \& Costa, A. (2020). Characterizing lexicalization and self-monitoring processes in bilingual speech production. Journal of Neurolinguistics, 56, 100934.

Chen, M., Ma, F., Wu, J., Li, S., Zhang, Z., Fu, Y., ... \& Guo, T. (2020). Individual differences in language proficiency shape the neural plasticity of language control in bilingual language production. Journal of Neurolinguistics, 54, 100887.

Hitomi, T., Gerrits, R., \& Hartsuiker, R. (in press). Using functional near-infrared spectroscopy to study word production in the brain: A picture-word interference study. Journal of Neurolinguistics.

Kemmerer, D. (2019). Messages must be tuned to the target language: Some implications of crosslinguistic semantic diversity for neurolinguistic research on speech production. Journal of Neurolinguistics, 52, 100861. 
Nozari, N., \& Pinet, S. (2020). A critical review of the behavioral, neuroimaging, and electrophysiological studies of co-activation of representations during word production. Journal of Neurolinguistics, 53, 100875.

Piai, V., Klaus, J., \& Rossetto, E. (2020). The lexical nature of alpha-beta oscillations in context-driven word production. Journal of Neurolinguistics, 55, 100905.

Ries, S., Tavildar, S., Rohilla, R., Sperling, C., \& Ashrafi, A. (2020). Patterns of cortical interactivity supporting speech production and lexical retrieval: A graph signal processing approach at the individual level. Journal of Neurolinguistics, 56, 100936.

Runnqvist, E., Santesteban, M., Hernandez, M., Navarrete, E., Baus, C., Martin, C.,... \& Mahon, B. (in press). Albert Costa: Memories of language production and bilingualism. Journal of Neurolinguistics.

Strijkers, K., \& Costa, A. (2012). The neurocognition of language production: Introduction to the special topic. Frontiers in psychology, 3, 198.

Zeng, T., Branigan, H. P., \& Pickering, M. J. (2020). Do bilinguals represent between-language relationships beyond the word level in their lexicon?. Journal of Neurolinguistics, 55, 100892.

Zhang, H., Wu, Y. J., \& Thierry, G. (2020). Bilingualism and aging: A focused neuroscientific review. Journal of Neurolinguistics, 54, 100890. 